
ing by the publisher. To access the final edited and published work see http://pubs.acs.org/doi/abs/10.1021/jacs.6b07999.

\title{
Acid activation in phenyliodine dicarboxylates: direct observation, structures and implications
}

\author{
Susana Izquierdo, ${ }^{\mathrm{a}}$ Stéphanie Essafi, ${ }^{\mathrm{b}}$ Iker del Rosal, ${ }^{\mathrm{b}}$ Pietro Vidossich, ${ }^{\mathrm{b}}$ Roser Pleixats, ${ }^{\mathrm{b}}$ Adelina \\ Vallribera, ${ }^{\mathrm{b}}$ Gregori Ujaque, ${ }^{\mathrm{b}}$ Agustí Lledós, ${ }^{* \mathrm{~b}}$ Alexandr Shafir*a \\ anstitute of Chemical Research of Catalonia (ICIQ), Barcelona Institute of Science and Technology, Av. Països Cata-

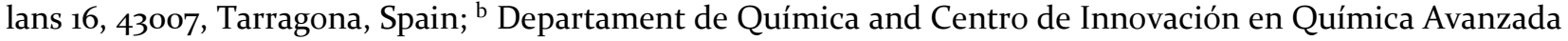 \\ (ORFEO-CINQA), Universitat Autònoma de Barcelona, 08193 Cerdanyola del Vallès, Spain.
}

Supporting Information Placeholder

\begin{abstract}
The use of the hypervalent iodine reagents in oxidative processes has become a staple in modern organic synthesis. Frequently, the reactivity of $\lambda^{3}$ iodanes is further enhanced by acids (Lewis or Brønsted). The origin of such activation, however, has remained elusive. Here, we use the common combination of $\mathrm{PhI}(\mathrm{OAc})_{2}$ with $\mathrm{BF}_{3} \cdot \mathrm{Et}_{2} \mathrm{O}$ as model to fully explore this activation phenomenon. In addition to the spectroscopic assessment of the dynamic acid-base interaction, for the first time the putative PIDA. $\mathrm{BF}_{3}$ complex has been isolated and its structure determined by $\mathrm{X}$-Ray diffraction. Consequences of such activation are discussed from a structural and electronic (DFT) points of views, including the origins of the enhanced reactivity.
\end{abstract}

Although known for over a century, ${ }^{1}$ organoiodine(III) reagents have gained significant importance in recent years, becoming an important go-to tool in a number of synthetic processes. ${ }^{2,3}$ Among the most commonly used iodine(III) reagents are phenyliodine(III) dicarboxylates, obtained either through oxidation of iodobenzene, or by treating the polymeric iodosobenzene $\mathrm{PhI}=\mathrm{O}$ with the corresponding carboxylic acid (Equation 1). Phenyliodine diacetate, PIDA, and phenyliodine bis(trifluoroacetate), PIFA are the most prominent members of this family.

$$
\underset{\substack{\text { iodosylbenzene } \\ \text { "Phl=O" }}}{\stackrel{\mathrm{RCOOH}}{-\mathrm{H}_{2} \mathrm{O}}}
$$

While $\lambda^{3}$ iodanes may be quite reactive, their reactivity is frequently further enhanced by an acid additive, either Lewis or Brønsted. Indeed, hundreds of transformations have been reported requiring the inclusion of such activators, often chosen from among $\mathrm{BF}_{3} \cdot \mathrm{Et}_{2} \mathrm{O}, \mathrm{HOTf}, \mathrm{Me}_{3} \mathrm{SiOTf}$ or $\mathrm{Me}_{3} \mathrm{SiBr}$. Combinations of PIDA or PIFA with $\mathrm{BF}_{3} \cdot \mathrm{Et}_{2} \mathrm{O}$ have proven particularly versatile, as seen in the formation of $\lambda$-diaryliodanes 4 and the oxidation of alcohols, 5 the dehydrogenative arene-arene coupling, ${ }^{6}$ arene functionalization, ${ }^{7}$ olefin diacetoxylation, ${ }^{8}$ or a variety of rearrangement ${ }^{9}$ and $\mathrm{C}-\mathrm{O}, \mathrm{C}-\mathrm{N}$ and $\mathrm{C}-\mathrm{S}$ cyclization reactions. $^{10}$

In our own research, and building upon earlier findings by Kita et al., the PIFA/ $\mathrm{BF}_{3} \cdot \mathrm{Et}_{2} \mathrm{O}$ combination was used for direct dehydrogenative synthesis of polynaphthalenes. ${ }^{11}$ Importantly, no coupling took place in the absence of the Lewis acid. Surprisingly, despite its recognized importance, the role played by the acid additives in iodine(III) chemistry is seldom addressed, beyond the general assumption of the formation of a more reactive $\mathrm{PhI}(\mathrm{OAc})^{+}$cation (Figure 1 ).

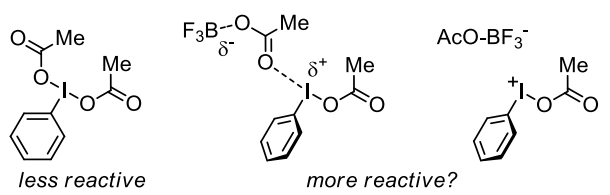

Figure 1. Hypothetical activation of $\mathrm{PhI}(\mathrm{OAc})_{2}$ by a Lewis acid.

Kang and Gade proposed that HOTf might act as catalyst in olefin dioxygenation with $\mathrm{PhI}(\mathrm{OAc})_{2}$, through the formation of the $[\mathrm{PhI}(\mathrm{OAc})]^{+}$cation. ${ }^{12}$ This species was actually detected by ESI+ spectrometry, yet it is already present in the mass spectrum of non-activated $\mathrm{PhI}(\mathrm{OAc})_{2}$ in $\mathrm{CH}_{3} \mathrm{CN}^{13}$ and may thus arise from MS-related ionization processes. Direct observation of this cation under experimentally relevant conditions would certainly support mechanistic hypothesis based on the enhanced reactivity of $[\mathrm{PhI}(\mathrm{OAc})]^{+}$cation. On this basis, we sought firmer structural evidence for acid activation phenomenon by studying the ubiquitous $\mathrm{PIDA} / \mathrm{BF}_{3} \cdot \mathrm{Et}_{2} \mathrm{O}$ combination. The ${ }^{1} \mathrm{H}$ NMR spectrum of $\mathrm{PhI}(\mathrm{OAc})_{2}$ was recorded in $\mathrm{CDCl}_{3}$ with and without $\mathrm{BF}_{3} \cdot \mathrm{Et}_{2} \mathrm{O}$ present. The addition of the Lewis acid (1 equiv) caused a downfield displacement ( 0.1 ppm) of the aromatic resonances, consistent with the formation of a more electron-deficient species (Figure 2). Free $\mathrm{Et}_{2} \mathrm{O}$ was also observed, confirming the liberation of the $\mathrm{BF}_{3}$ unit. Portionwise addition of $\mathrm{BF}_{3} \cdot \mathrm{Et}_{2} \mathrm{O}$ caused a gradual displacement of the $o$-Ph resonance from $8.08 \mathrm{ppm}$ up to $8.19 \mathrm{ppm}$, with the latter value reached at approx. 1.2 equiv (Figure 2); a parallel change was observed for the meta and para hydrogens and for OAc. 


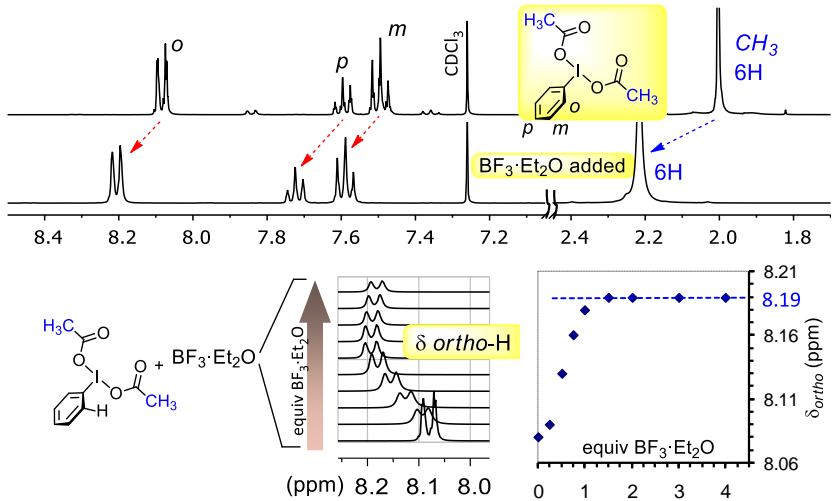

Figure 2. ${ }^{1} \mathrm{H}$ NMR spectra of PIDA with and without $\mathrm{BF}_{3} \cdot \mathrm{Et}_{2} \mathrm{O}$, and ${ }^{1} \mathrm{H}$ NMR titration plot $\left(\delta_{\text {ortho }}\right.$ ) of PIDA with $\mathrm{BF}_{3} \cdot \mathrm{Et}_{2} \mathrm{O}$.

No further displacement was observed with additional portions of the Lewis acid, which is in line with a 1:1 stoichiometry in the PIDA- $\mathrm{BF}_{3}$ adduct. The continuous displacement of the ${ }^{1} \mathrm{H}$ NMR resonances suggests a rapid $\mathrm{BF}_{3}$ hopping between molecules of PIDA, leading to a weight-averaged chemical shift. Furthermore, the presence of a single acetate resonance $(6 \mathrm{H})$ suggests either a symmetrical species, or a rapid $\mathrm{BF}_{3}$ exchange between the two acetate sites. The latter scenario was confirmed by cooling a 1:1 $\mathrm{PIDA} / \mathrm{BF}_{3}$ solution to $-53^{\circ} \mathrm{C}$, which rendered the two distinct $\mathrm{OAc}\left({ }_{3} \mathrm{H}\right.$ and $\left.{ }_{3} \mathrm{H}\right)$ signals clearly distinguishable (Figure 3).
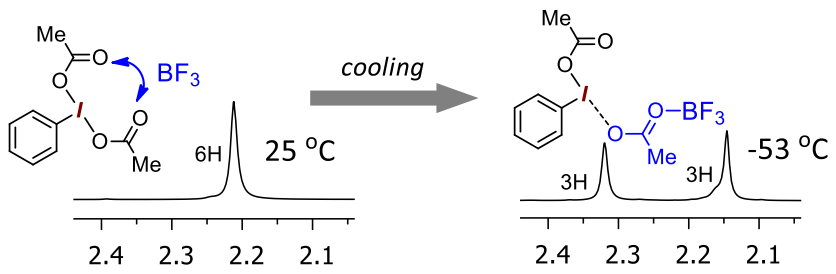

Figure 3. Variable temperature $1 \mathrm{H}$ NMR spectrum of the 2:1 mixture of PIDA and PIDA $\cdot \mathrm{BF}_{3}$. At $-50{ }^{\circ} \mathrm{C}$ the coexistence of the two species is clearly distinguishable.

Due to fast $\mathrm{BF}_{3}$ hopping, a single time-averaged set of ${ }^{1} \mathrm{H}$ NMR resonances is observed for a 2:1 mixture of PIDA and $\mathrm{BF}_{3} \cdot \mathrm{Et}_{2} \mathrm{O}$, expected to contain an equimolar PIDA / PIDA. $\mathrm{BF}_{3}$ mixture. Nevertheless, at $-50^{\circ} \mathrm{C}$ the pattern was resolved into two sets

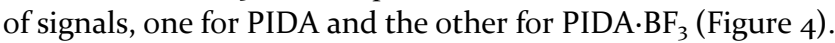
From the coalescence temperature $(\sim 260 \mathrm{~K})$ the $\Delta \mathrm{G}^{\ddagger}$ barrier for $\mathrm{BF}_{3}$ hopping was estimated to be $\sim 9 \mathrm{kcal} / \mathrm{mol}$ (see Support. Info).

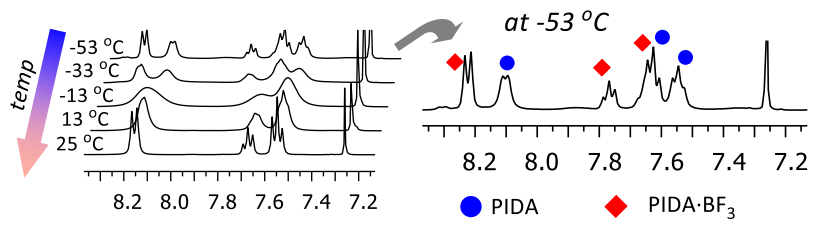

Figure 4. Coexistence of the clearly distinguishable PIDA and PIDA $\cdot \mathrm{BF}_{3}$ at $-53^{\circ} \mathrm{C}$.

Having assessed the nature of a putative $\mathrm{PhI}(\mathrm{OAc})_{2} \cdot \mathrm{BF}_{3}$ complex by solution NMR, we sought to access this species synthetically. It was found that the addition of 1.5 equiv of $\mathrm{BF}_{3} \cdot \mathrm{Et}_{2} \mathrm{O}$ to a solution of $\mathrm{PhI}(\mathrm{OAc})_{2}$ in a 1:1 hexane $/ \mathrm{CH}_{2} \mathrm{Cl}_{2}$ mixtures led, after $1 \mathrm{~h}$, to the appearance of a white precipitate, which was isolated by filtration under $\mathrm{N}_{2}$ atmosphere. The ${ }^{1} \mathrm{H}$ and ${ }^{19} \mathrm{~F}$ NMR of this solid confirmed the formulation as $\mathrm{PhI}(\mathrm{OAc})_{2} \cdot \mathrm{BF}_{3}$, isolated in an $87 \%$ yield (Scheme 1 ). For the first time, crystals suitable for $\mathrm{X}$-Ray diffraction were obtained as colorless needles from a $\mathrm{CH}_{2} \mathrm{Cl}_{2}$ solution via a slow diffusion-exchange with $n$-hexane. The structure presents discreet units of $\mathrm{PhI}(\mathrm{OAc})_{2} \cdot \mathrm{BF}_{3}$ with the $\mathrm{BF}_{3}$ moiety bound to the distal $\mathrm{O}$ atom of one of the OAc ligands. Comparison with the structure of $\mathrm{PhI}(\mathrm{OAc}){ }_{2}{ }^{14}$ reveals a geometrically analogous arrangement around the $\lambda^{3}$ iodine and a similar $\mathrm{C}_{\mathrm{Ph}}-\mathrm{I}$ bond length (2.099 $\AA$ ). However, the new adduct features the elongation of the I-O bond from 2.15 $\AA$ (average in PIDA) to 2.28 $\AA$ for the $\mathrm{OAc} \cdot \mathrm{BF}_{3}$ group. Given the strong trans influence in $\lambda^{3}$ iodanes, ${ }^{15}$ this lengthening is accompanied by the shortening of the complementary I-OAc bond to $2.076 \AA$. These structural features are consistent with the development of partially cationic character, namely, with $[\mathrm{PhI}(\mathrm{OAc})]^{+}$. We then proceeded to extend this study to other iodanes / acid systems. Surprisingly, no interaction between phenyliodine bis(trifluoroacetate), PIFA, and $\mathrm{BF}_{3} \cdot \mathrm{Et}_{2} \mathrm{O}$ was observed by $\mathrm{NMR}^{16}$ even in the presence of 8 equiv of $\mathrm{BF}_{3} \cdot \mathrm{Et}_{2} \mathrm{O}$. This reactivity difference between PIDA and PIFA appears to stem from the much lower basicity of PIFA.

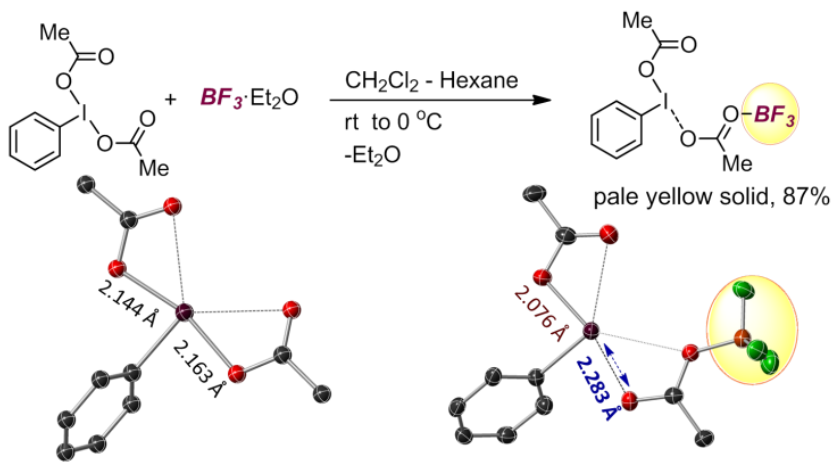

Scheme 1. Synthesis and structure of $\mathrm{PhI}(\mathrm{OAc})_{2} \cdot \mathrm{BF}_{3}$.

For further insight, two additional analogs were prepared, the monofluoroacetate $\mathrm{PhI}\left(\mathrm{OCOCH}_{2} \mathrm{~F}\right)_{2}, \mathbf{1}^{17}$ and bis-difluoroacetate $\mathrm{PhI}\left(\mathrm{OCOCHF}_{2}\right)_{2}, \mathbf{2}$. Both were obtained through the oxidation of iodobenzene with $\mathrm{Oxone}^{\circledR}$ in the presence of the corresponding carboxylic acid (Scheme 2 ). ${ }^{18}$ In the case of $\mathbf{1}$, the addition of $\mathrm{BF}_{3} \cdot \mathrm{Et}_{2} \mathrm{O}$ caused a displacement of the ${ }^{1} \mathrm{NMR}$ signal as already observed for $\mathrm{PhI}(\mathrm{OAc})_{2}$, indicating sufficient basicity to form a $\mathbf{1} \cdot \mathrm{BF}_{3}$ adduct. When conducted in $\mathrm{CH}_{2} \mathrm{Cl}_{2}$, this addition caused the formation of a white crystalline $\mathbf{1} \cdot \mathrm{BF}_{3}$; both $\mathbf{1}$ and $\mathbf{1} \cdot \mathrm{BF}_{3}$ were characterized by single crystal X-Ray diffraction (Scheme 2). Once again, the adduct can be described as a weakly bound ion pair between $\left[\mathrm{PhI}\left(\mathrm{O}_{2} \mathrm{CCFH}_{2}\right)^{+}\right.$and the $\mathrm{FH}_{2} \mathrm{CCOO} \cdot \mathrm{BF}_{3}-$ anion. In contrast, the bis-difluoroacetate 2 behaved much like PIFA, and gave no indication by ${ }^{1} \mathrm{H}$ NMR of interacting with $\mathrm{BF}_{3} \cdot \mathrm{Et}_{2} \mathrm{O}$.

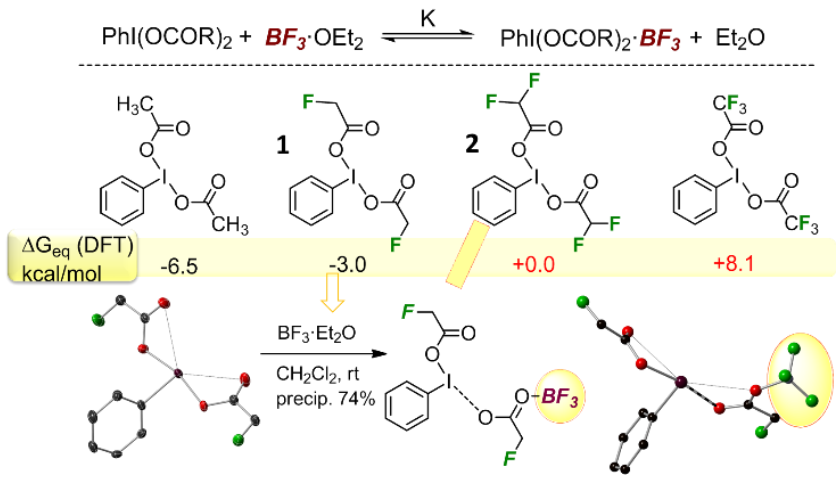


Scheme 2. The range of phenyliodine dicarboxylates explored, along with the synthesis and X-Ray structure of $\mathbf{1} \cdot \mathrm{BF}_{3}$. Calculated $\Delta \mathrm{G}$ for the formation equilibrium.

This data are indicative of an acid-base equilibrium, whereby the $\lambda$ 3-iodane and the $\mathrm{Et}_{2} \mathrm{O}$ molecule compete for the $\mathrm{BF}_{3}$ unit, with the equilibrium shifted toward the $\mathrm{BF}_{3}$ adduct for the more basic PIDA and $\mathbf{1}$. In contrast, for $\mathbf{2}$ as well as PIFA, this equilibrium is shifted far to the left (Scheme 2). DFT calculations support this interpretation, with calculated Gibbs energy for the equilibria in Scheme 2 decreasing in the order $+8.1 \mathrm{kcal}$ $\mathrm{mol}^{-1}\left(\mathrm{CF}_{3}\right)$, o.o $\left(\mathrm{CHF}_{2}\right)$, -3.o $\left(\mathrm{CH}_{2} \mathrm{~F}\right)$ and -6.5 $\left(\mathrm{CH}_{3}\right)$. Nevertheless, even for PIFA, there would be a finite small concentration of the $\mathrm{BF}_{3}$-activated species, possibly responsible for the increased reactivity. For the mildly basic 1, NMR titration allowed contrasting the computational estimate with the experimental measure (Figure 5). The observed chemical shift is a weighted average of chemical shifts of the free $\mathbf{1}$ and $\mathbf{1} \cdot \mathrm{BF}_{3}$ (Equation a in Fig. 5). Therefore, $\delta_{\text {obs }}$ provides a direct measure of the extent of reaction, $x$, which, in turn, depends directly on the equilibrium constant $\mathrm{K}$ (Equation $\mathbf{b}$ in Fig. 5). By fitting the theoretical $\delta$ curves, obtained by solving equations $\mathbf{a}$ and $\mathbf{b}$ in Figure $5,{ }^{19}$ to the experimental chemical shifts $\delta_{\text {exp }}$, an optimal values of $\mathrm{K}=3.3$ and $\Delta \mathrm{G}_{\text {exp }}=-1.1 \mathrm{kcal} / \mathrm{mol}$ were obtained (Figure 5).

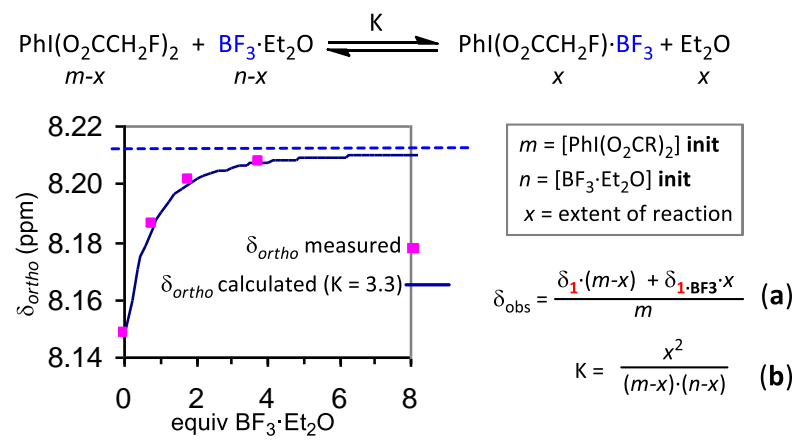

Figure 5. Dependence of the $\delta_{\text {ortho }}$ for 1 on the amount of $\mathrm{BF}_{3} \cdot \mathrm{Et}_{2} \mathrm{O}$ added; $\mathrm{m}=\left[\mathrm{PhI}\left(\mathrm{O}_{2} \mathrm{CR}\right)_{2}\right]_{\text {init }} ; \mathrm{n}=\left[\mathrm{BF}_{3} \cdot \mathrm{Et}_{2} \mathrm{O}\right]_{\text {init }} ; \mathrm{x}$ is extent of reaction.

We complemented our study by treating PIDA with TMSOTf, commonly employed in iodine(III) activation. The reaction afforded $\mathrm{PhI}(\mathrm{OAc})$ (OTf) (76\% yield), a species previously obtained by Stang and coworkers from $\mathrm{PhI}=\mathrm{O}$, and recently observed (MS, ${ }^{1} \mathrm{H}$ NMR) by the groups of Gade ${ }^{12}$ and Dutton (Scheme 3). ${ }^{20}$ While the compound is highly unstable, Ochiai, Miyamoto and co-workers did characterized its hydrolysis (aqua) product in the presence of [18]crown-6.. ${ }^{21}$ Now, X-Ray quality crystals of this reagent were obtained by storing a $\mathrm{CH}_{2} \mathrm{Cl}_{2}$ solution at $-25^{\circ} \mathrm{C}$ under argon. The structure is consistent with a weakly bound ionic pair between $\mathrm{PhI}(\mathrm{OAc})^{+}$and OTf, with a rather long I-OTf distance $(2.35 \AA)$ and the I-OAc bond of $2.056 \AA$, which is even shorter than in the $\mathrm{BF}_{3}$ adduct. Incidentally, attempts at crystallization also produced a second set of crystals, now corresponding to the dimeric [PhI$\mathrm{OIPh}](\mathrm{OTf})_{2}$, i.e. the Zefirov's reagent, often employed as a HOTf-activated PhIO equivalent. ${ }^{22}$ This has allowed for the solid state structure of this reagent to be determined for the first time (Scheme 3).

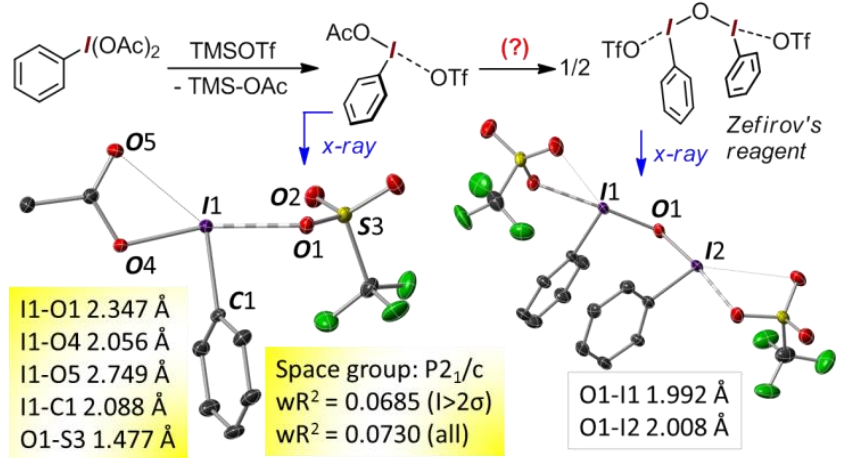

Scheme 3. Formation and X-Ray structure of $\mathrm{PhI}(\mathrm{OAc})(\mathrm{OTf})$ and the dimeric Zefirov's reagent.

As mentioned in the introduction, acid activation is supposed to promote the formation of species with enhanced [PhI$\mathrm{OAc}^{+}$cation character. From a molecular orbital point of view, activation lowers the energy of LUMO, rendering the resulting species a stronger Lewis acid and oxidant. Within the three-level hypervalent bonding model, $, 2,3$ the LUMO in PIDA is a p-type orbital centered on iodine and aligned with the $\mathrm{O}$ $\mathrm{I}-\mathrm{O}$ vector. DFT calculations show a clear correlation between LUMO energies for a range of the $\mathrm{PhI}(\mathrm{OAc})-\mathrm{X}$ species and the coordinating ability of the $\mathbf{X}^{-}$anion (Figure 6). In PIDA, the LUMO orbital is at $-1.9 \mathrm{eV}$, and this energy is lowered to different extents by converting one of the acetate ligands into a less coordinating $\mathbf{X}$ anion. Binding of $\mathrm{BF}_{3}$ generates $\mathrm{X}$ $=\mathrm{OAc} \cdot \mathrm{BF}_{3}$ and lowers the LUMO energy to $-2.59 \mathrm{eV}$, while in the $\mathrm{PhI}(\mathrm{OAc})(\mathrm{OTf})$ complex this energy is $-2.77 \mathrm{eV}$. Simply put, acid activation tends to generate a species more akin the cationic $[\mathrm{PhI}(\mathrm{OAc})]^{+}$with the LUMO energy of $-4.19 \mathrm{eV}$.

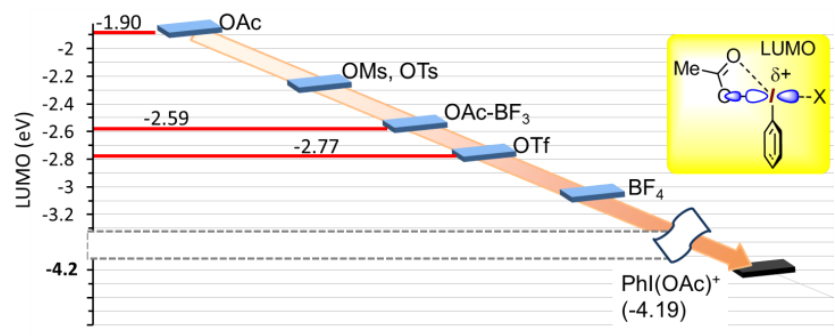

Figure 6. DFT calculated LUMO energies $(\mathrm{eV})$ for several $\mathrm{PhI}(\mathrm{OAc})-\mathrm{X}$ species.

We then verified the synthetic relevance of the isolated activated species by testing its reactivity in transformations known to proceed in the presence of the PIDA/ $\mathrm{BF}_{3} \cdot \mathrm{Et}_{2} \mathrm{O}$ combinations. Thus, the oxidative cyclization of the $\mathrm{N}$-allyl benzamide 3 to oxazoline $4,{ }^{23}$ proceeded smoothly both with a mixture of PIDA/ $/ \mathrm{BF}_{3} \cdot \mathrm{Et}_{2} \mathrm{O}$ and with the preformed PIDA. $\mathrm{BF}_{3}$; importantly, no reaction took place with PIDA alone (Scheme 4).

$$
\begin{aligned}
& \mathrm{Ph} /(\mathrm{OAc})_{2}+\mathrm{BF}_{3} \cdot \mathrm{Et}_{2} \mathrm{O} \\
& \mathrm{Ph} /(\mathrm{OAc})_{2}+\mathrm{P}_{3}
\end{aligned}
$$

Scheme 4. The effect of acid activation on the formation of the oxazoline 4 from 3 with PIDA.

We also tested an interesting usage of PIDA as a $\mathrm{C}_{6} \mathrm{H}_{5} \mathrm{I}$ building block via ortho propargylation. In the original report by Ochiai et al. ${ }^{24}$ described the formation of the ortho-propargyl 
iodobenzene from $\mathrm{PhI}(\mathrm{OAc})_{2}$ and propargylsilane in the presence of $\mathrm{BF}_{3} \cdot \mathrm{Et}_{2} \mathrm{O}$. Hence, the coupling was tried using propargylsilanes bearing the terminal $\mathrm{R}=\mathrm{H}$ (5a) and $\mathrm{R}=$ cyclohexyl (5b) groups. As seen in Scheme 5, while PIDA itself was unreactive, respectable yields of the corresponding ortho-propargyl iodobenzenes $\mathbf{6 a}$ and $\mathbf{6} \mathbf{b}$ were indeed obtained either by introducing $\mathrm{BF}_{3} \cdot \mathrm{Et}_{2} \mathrm{O}$ (1 equiv) or by using the pre-formed $\mathrm{PIDA} \cdot \mathrm{BF}_{3}$ and $\mathrm{PhI}(\mathrm{OAc})(\mathrm{OTf}) ; 25$ this behavior argues in favor of the synthetic relevance of the newly prepared Lewis-acid activated complex.
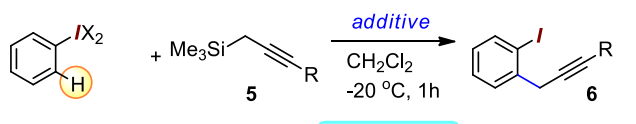

\begin{tabular}{ccccc}
\multicolumn{2}{c}{$\begin{array}{c}\mathrm{Phl}(\mathrm{OAc})_{2} \\
\text { additive }\end{array}-\begin{array}{c}\mathrm{Phl}(\mathrm{OAc})_{2} \\
\mathrm{BF}_{3} \cdot \mathrm{Et}_{2} \mathrm{O}\end{array}$} & $\begin{array}{c}\mathrm{Ph} \mid(\mathrm{OAc})_{2} \cdot \mathrm{BF}_{3} \\
--\end{array}$ & $\begin{array}{c}\mathrm{Phl}(\mathrm{OAc})(\mathrm{OTf}) \\
--\end{array}$ \\
$\mathrm{R}=\mathrm{H}, \mathbf{6 a}$ & $0 \%$ & $82 \%$ & $72 \%$ & $86 \%$ \\
$\mathrm{R}=\mathrm{Cy}, \mathbf{6 b}$ & $0 \%$ & $69 \%$ & $57 \%$ & $42 \%$
\end{tabular}

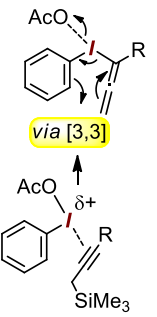

Scheme 5. The effect of acid activation on the ortho-propargylation of $\mathrm{PhI}(\mathrm{OAc})_{2}$.

We also investigated the significant rate acceleration for the reaction between $\mathrm{PhI}(\mathrm{OAc})_{2}$ and mesitylene ushered by $\mathrm{BF}_{3} \cdot \mathrm{Et}_{2} \mathrm{O}$. When PIDA alone was used in $\mathrm{CDCl}_{3}$, no reaction was detected at $25^{\circ} \mathrm{C}$ after $60 \mathrm{~min}$. The addition of $\mathrm{BF}_{3} \cdot \mathrm{Et}_{2} \mathrm{O}$ led to an immediate (<10 sec) quantitative (NMR) formation of the corresponding diaryl iodane $\mathrm{Ph}(\mathrm{Mes}) \mathrm{I}-\mathrm{OAc}$ (Scheme 6)

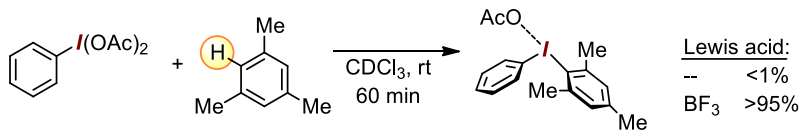

Scheme 6. The effect of $\mathrm{BF}_{3}$ activation on the formation of a diaryl $\lambda^{3}$ iodane.

These results argue in favor of synthetic relevance of the newly prepared Lewis-activated complex, suggesting, in both cases, that a cationic $[\mathrm{PhI}(\mathrm{OAc})]^{+}$character facilitates the crucial interaction between the iodine(III) center and the substrates $\pi$ system.

A DFT mechanistic study of the reactivity of PIDA towards mesitylene was undertaken to unravel the effect of the Lewis additive assuming an $\mathrm{S}_{\mathrm{E}} \mathrm{Ar}$ process (Figure 7 ). For the reaction to take place, mesitylene required cis binding to the $\mathrm{Ph}$ ligand (the strongest trans-directing ligand). This was made possible by a movement of the OAc to a position trans to $\mathrm{Ph}$, which, in the absence of a Lewis acid, proceeds with a barrier of $19.8 \mathrm{kcal}$ mol-1 $^{-1}$ (TS-I-II, Fig. 6). In contrast, binding of the $\mathrm{BF}_{3}$ group greatly facilitates the "slipping" of the resulting anion (TS-III-BF3 Figure 6). The subsequent binding of mesitylene is favorable. The reaction is completed by the acetate-assisted $\mathrm{C}$ $\mathrm{H}$ deprotonation to restore the aromaticity of the mesitylene ring. This step is also favored by $\mathrm{BF}_{3}$ (TS-III-IV). Thus, in this case $\mathrm{BF}_{3}$ promotes the reactivity at two levels: by favoring the intramolecular pre-arrangement of the $\lambda$-iodane and by lowering the activation barrier of the bond breaking event.

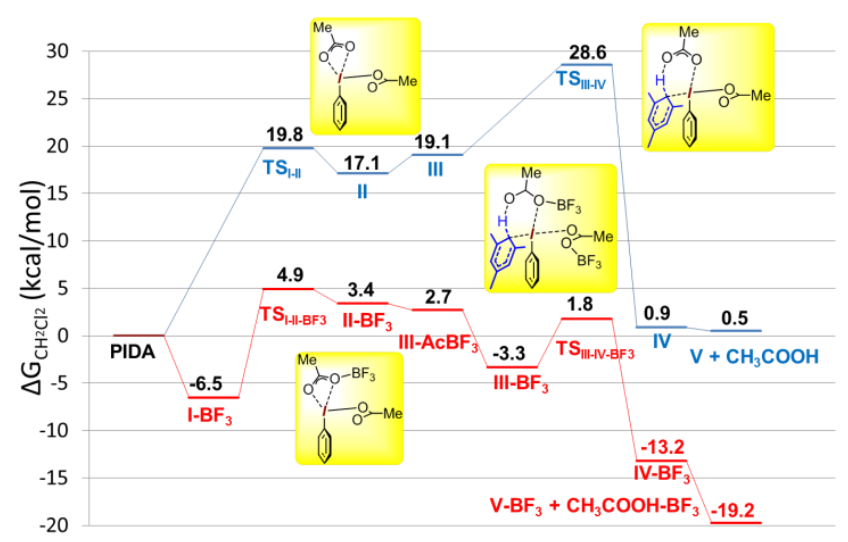

Figure 7. DFT Gibbs energy profile in $\mathrm{CH}_{2} \mathrm{Cl}_{2}$ ) for the reaction between PIDA and mesitylene with and without $\mathrm{BF}_{3} \cdot \mathrm{Et}_{2} \mathrm{O}$.

In summary, the phenomenon of acid activation of simple $\lambda_{3}$ iodane has been studied for the model $\mathrm{PhI}\left(\mathrm{O}_{2} \mathrm{CCR}\right)_{2}$ by NMR, DFT and through synthetic approaches, including the isolation and single crystal characterization of the two key species, $\mathrm{PhI}(\mathrm{OAc}) \cdot \mathrm{BF}_{3}$ and $\mathrm{PhI}(\mathrm{OAc})(\mathrm{OTf}) .{ }^{26}$ Surprisingly, no interaction between PIFA and $\mathrm{BF}_{3} \cdot \mathrm{Et}_{2} \mathrm{O}$ was detected by NMR. Lowering of the LUMO energy is proposed as key for the activation phenomenon. As a word of caution, it is important to emphasize that, depending on the reaction, the role of acid additives may go beyond the activation of the iodane species, through participation in further phenomena, e.g. in radical caging, catalyst or substrate activation or fluoride transfer. Nevertheless, we expect that detailed understanding of the effect exerted by acids on the hypervalent iodine reagent will assist researchers in studying the mechanisms involving such species and in the development of new stoichiometric and catalytic oxidative transformations.

\section{ASSOCIATED CONTENT}

\section{Supporting Information}

NMR data, synthetic procedure, product characterization, single crystal diffraction studies, DFT methodology employed and Cartesian coordinates and energies of all the optimized structures. This material is available free of charge via the Internet at http://pubs.acs.org.

\section{AUTHOR INFORMATION}

\section{Corresponding Author}

*agusti@klingon.uab.es

*ashafir@iciq.es

Notes

The authors declare no competing financial interests.

\section{ACKNOWLEDGMENT}

This work was funded by Fundació ICIQ, MINECO (CTQ201346705-R, CTQ2014-54071-P, CTQ2014-53662-P, 2014-2018 Severo Ochoa Excellence Accreditation SEV-2013-0319 and CTQ2014-51912-REDC) and the Generalitat de Catalunya (2014 SGR 1192, 2014 SGR 1105). The CELLEX Foundation is gratefully acknowledged for a post-doctoral contract to S. I. and for support through the CELLEX-ICIQ HTE platform.

\section{REFERENCES}


(1) For an historical perspective, see Varvoglis, A. Hypervalent Iodine in Organic Synthesis; Academic Press: London, 1997.

(2) a) Zhdankin, V. V.; Stang, P. J. Chem. Rev. 2002, 102, 2523-2584; b) Zhdankin, V. V.; Stang, P. J. Chem. Rev. 2008, 108, 5299-5358; c) Yoshimura, A.; Zhdankin, V. V. Chem. Rev. 2016, 116, 3328-3435.

(3) a) Hypervalent Iodine Chemistry. Modern Developments in Organic Synthesis, Editor: T. Wirth, Springer 2003; b) Singh, F. V.; Wirth, T. Chem. Asian J. 2014, 9, 950-971; c) Silva, L. F.; Olofsson, B. Nat. Prod. Rep. 2014, 28, 1722-1754.

(4) Merritt, E. A.; Olofsson, B. Angew. Chem. Int. Ed. 2009, 48, 9052 -9070 .

(5) Kida, M; Sueda, T.; Goto, S.; Okuyama T.; Ochiai, M. Chem. Commun. 1996, 1933-1934.

(6) For an early example; a) Tohma, H.; Iwata, M.; Maegawa, T.; Kiyono, Y.; Maruyama, A.; Kita, Y. Org. Biomol. Chem. 2003, 1, 16471649; for a review, see: b) Narayan, R.; Matcha, K.; Antonchick, A. P. Chem. Eur. J. 2015, 21, $14678-14693$.

(7) Liu, H.; Wang, X.; Gu, Y. Org. Biomol. Chem. 2011, 9, 1614-1620.

(8) Zhong, W.; Yang, J.; Meng, X.; Li, Z. J. Org. Chem. 2011, 76, 9997-10004.

(9) Ochiai, M.; Hirobe, M.; Yoshimura, A.; Nishi, Y.; Miyamoto, K.; Shiro, M. Org. Lett. 2007, 9, 3335-3338.

(10) a) Gu, Y.; Xue, K. Tetrahedron Lett. 2010, 51 192-196; b) Serna, S.; Tellitu, I.; Domínguez, E.; Moreno, I.; SanMartín, R. Tetrahedron Lett. 2003, 44, 3483-3486; c) Kita, Y.; Egi, M.; Ohtsubo, M.; Saiki, T.; Takada T.; Tohma H. Chem. Commun. 1996, 2225-2226.

(11) a) Dohi, T.; Ito, M.; Morimoto, K.; Iwata. M.; Kita, Y. Angew. Chem. Int. Ed. 2008, 47, 1301-1304; b) Faggi, E.; Sebastián, R. M.; Pleixats, R.; Vallribera, A.; Shafir, A.; Rodríguez-Gimeno, A; Ramírez de Arellano,C. J. Am. Chem. Soc. 2010, 132, 17980-17982; c) Guo, W.; Faggi, E.; Sebastián, R. M.; Vallribera, A.; Pleixats, R.; Shafir, A. J. Org. Chem. 2013, 78, 8169-8175.

(12) Kang, Y.-B.; Gade, L. H. J. Am. Chem. Soc. 2011, 133, 3658-3667.

(13) Silva, L. F.; Lopes, N. P. Tetrahedron Lett. 2005, 46, 6023-6027.

(14) Coordinates for PIDA from CSD (refcode IBZDAC12): Togo, H.; Nabana, Y.; Yamaguchi, K. J. Org. Chem. 20oo, 65, 8391-8394.
(15) a) Ochiai, M.; Sueda, T.; Miyamoto, K.; Kiprof, P.; Zhdankin, V. V. Angew. Chem. Int. Ed. 2006, 45, 8203-8206; b) Sajith, P. K.; Suresh, C. H. Inorg. Chem. 2012, 51, 967-977.

(16) An analogous PIFA-BF 3 interaction has been invoked as key for SET processes: Dohi, T.; Ito, M.; Yamaoka, N.; Morimoto, K.; Fujioka H.; Kita, Y. Tetrahedron 2009, 65, 10797-10815.

(17) Merkushev, E. B.; Novikov, A. N.; Makarchenko, S. S.; Moskal'chuk, A. S.; Glushkova, V. V.; Kogai, T. I.; Polyakova, L. G. Zh. Org. Khim. 1975, 11, 1259-1263.

(18) Protocol adapted from Zagulyaeva, A. A.; Yusubov, M. S.; Zhdankin, V. V. J. Org. Chem. 2010, 75, 2119-2122.

(19) See Supporting information for details

(20) a) Zhdankin, V. V.; Crittell, C. M.; Stang, P. J.; Zefirov, N. S. Tetrahedron Lett. 1990, 31, 4821-4825; b) Aprile, A.; Iversen, K. J.; Wilson, D. J. D.; Dutton, J. L. Inorg. Chem. 2015, 54, 4934-4939; for the related $\operatorname{ArI}(\mathrm{OTf})_{2}$, also see: c) Farid, U.; Wirth, T. Angew. Chem. Int. Ed. 2012, 51, 3462 -3465; d) Hu, B.; Miller, W. H.; Neumann, K. D.; Linstad, E. J.; DiMagno, S. G. Chem. Eur. J. 2015, 44, 6394 - 6398.

(21) a) Ochiai, M.; Miyamoto, K.; Yokota, Y.; Suefuji, T.; Shiro, M. Angew. Chem. Int. Ed. 2005, 51, 75-78; b) Miyamoto, K.; Yokota, Y.; Suefuji, T.; Yamaguchi, K.; Ozawa, T. Ochiai, M. Chem. Eur. J. 2014, 20, 5448-5452.

(22) Zefirov, N. S.; Zhdankin, V. V.; Dan'kov, Y. V.; Sorokin, V. D.; Semerikov, V. N.; Koz'min, A. S.; Caple R.; Berglund, B. A. Tetrahedron Lett. 1986, 27, 3971-3974.

(23) Moon, N. G.; Harned, A. M. Tetrahedron Lett. 2013, 54, 29602963.

(24) a) Ochiai, M.; Ito, T.; Takaoka, Y.; Masaki, Y. J. Am. Chem. Soc. 1991, 113, 1319-1323; b) for a mini-review on iodonio-Claisen rearrangements: Shafir, A. Tetrahedron Lett. 2016, 57, 2673-2682.

(25) See Supporting information for details.

(26) While this work was in preparation, the ability of fluorinated alcohols to activated PIDA via hydrogen bonding was reported: Colomer, I.; Batchelor-McAuley, C.; Odell, B.; Donohoe, T. J.; Compton, R. G. J. Am. Chem. Soc. 2016, 138, 8855-8861. 


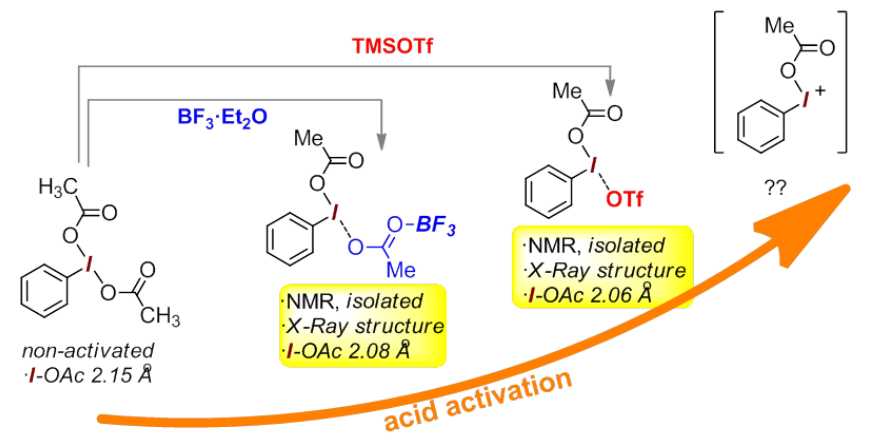

